\title{
Changes in Serum Lipid in First Trimester of Pregnancy
}

\author{
Moonmoon $\mathrm{THJ}^{1}$, Begum $\mathrm{K}^{2}$, Amanullah $\mathrm{M}^{3}$, Rabeya $\mathrm{S}^{4}$, Bari $\mathrm{MA}^{5}$
}

\begin{abstract}
A cross-sectional study was conducted in the department of Obstetrics \& Gynaecology, Bangabandhu Sheikh Mujib Medical University (BSMMU), Dhaka to determine the changes in serum lipid in 1st trimester of pregnancy over a period I year. A total of 91 subjects (60 women at first trimester of pregnancy assigned to case and 31 nonpregnant women with regular menstruation assigned to control) were included in the study. The mean age was significantly higher in control group than in case group $(27.0 \pm 4.3 v s$ 24.4 \pm 3.6 years respectively, $p=0.002)$. Lower socioeconomic class was predominance in case group (58.3\%) and middle class (53.7\%) in control group. The mean systolic and diastolic blood pressure was significantly higher in case group compared to control group. About $12 \%$ of patients had low HDL compared to $4.9 \%$ of controls $(p=0.240)$. Raised $L D L$ and raised triglycerides were found in $3.3 \%$ and $5 \%$ of the cases respectively while none of the control group had raised $L D L$ and triglyceride ( $p=0.350$ and $p=0.25$ respectively). The systolic and diastolic blood pressure was positively correlated with total cholesterol and HDL. However, $L D L$ and triglyceride exhibit negative linear relationship in the both systolic and diastolic blood pressure. From this study, it can be concluded that pregnant mothers in their trimester had slightly altered serum lipids compared to their nonpregnant counterpart.
\end{abstract}

Key words: Gestation, Lipoprotien, Cholesterol.

\section{Introduction}

Pregnancy is accompanied by significant variations in maternal lipid metabolism. In early pregnancy, there in

1. Corresponding Author:

Dr. T.H. Johra Moonmoon FCPS, MS

Medical Officer

Bangladesh Association of Venereology \& sterilization

Mirpur-2, Dhaka

E-mail: dr.thjohra@yahoo.com

2. Professor Kohinoor Begum Professor of Obs \& Gynae

Bangladesh Medical College \& Hospital

Dhanmondi, Dhaka

3. Dr. Masuma Amanullah MBBS, FCPS Junior Consultant Upzela Health Complex, Itna, Kishorgonj

4. Dr. Sultana Rabeya MBBS, M Phil Senior Medical Officer Patuakhali Science \& Technology University, Patuakhali

5. Dr. Md. Anwarul Bari Assistant Professor of Department of Medicine Sir Salimullah Medical College, Dhaka increased body fat accumulation associated with both hyperphagia and increased lipogenesis while in late pregnancy there is an accelerated breakdown of fat depots, which plays an important role in foetal development. It has been observed that the concentration of serum total cholesterol, serum triglyceride, high density lipoprotein cholesterol and low density lipoprotein cholesterol in normal pregnant women increased with increasing gestational age ${ }^{1}$. The present study was undertaken to elucidate any significant variation in the lipid profile during normal pregnancy in the different trimesters, to establish if pregnancy affects the lipid profile and to evaluate the clinical significance of the lipid level in pregnancy.

In the course of normal gestation, serum lipid and lipoprotein levels undergo variations, and triglycerides (TG), cholesterol and phospholipids are elevated. These changes are considered a reflection of increased metabolic demands by the mother's organism ${ }^{2}$. Serum low-density lipoprotein cholesterol (LDL) levels increase as gestation, peaking at 36 week gestation, probably due to the hepatic effects of estradiol and progesterone. High-density lipoprotein cholesterol (HDL) levels increase until reaching a peak at 25 weeks, decreasing thereafter until the $32 \mathrm{nd}$ week, after which values remain constant until birth. It is thought that estrogen is responsible for elevating HDL levels during the first half of gestation. Maternal progesterone-induced lipoprotein lipase activity leads to hypertriglyceridemia ${ }^{3}$. Pre-eclampsia (PE), a nonconvulsive from of pregnancy-induced hypertension, occurs in 5 to $10 \%$ of gestations. It accounts for a significant proportion of maternal and fetal morbidity and mortality ${ }^{4}$. PE in more frequent in first-gestation young women and in older multiparous women ${ }^{5}$. Endothelial injury is a key event in the pathogenesis of PE, occurring due to multiple factors. The typical uteroplacental lesion in PE is necrotizing arteriopathy. It has been shown that lipids accumulate in arterial intima cells and in macrophages. The similarity between lesions in PE and in arteriosclerosis has raised speculation about a common pathophysiological pathway ${ }^{6}$. Although data are scarce and inconsistent, marked hyperlipidemia has been observed in PE patients compared to women with pregnancies. PE in thus characterized by profound lipid changes similar to those found in atherosclerosis, including hypertriglyceridemia and relatively increased LDL levels, both of which play a role in endothelial injury and dysfunction. Decreased HDL serum levels were also related to $\mathrm{PE}^{5}$. There are, however, few studies assessing lipid profile changes changes early in pregnancy and the progression to PE. The purpose of this study was to evaluate serum TC, TG, LDL and HDL levels in pregnant women aged over 35 years during the first trimesters of pregnancy. 


\section{Materials and Methods}

A total of 991 subjects (60 women at first trimester of pregnancy were assigned as case and 31 non-pregnant healthy women with regular menstruation were assigned as control) were included in this study. The serum lipid profile (Total cholesterol, HDL, LDL and Triglyeerides) of pregnant women of first trimester were determined by enzymatic method during their first trimester and also serum lipid profile of non pregnant women were determined in the same method at the department of obstetrics and Gynecology in a tertiary hospital in Bangladesh. Estimation of total cholesterol: Serum total cholesterol was estimated by enzymatic method. Estimation of HDL cholesterol: Phosphotungstic acid in conjunction with magnesium chloride precipitates LDL and VLDL fraction of the sera, leaving HDL-C fraction in the solution. From the supernatant obtained after centrifugation, cholesterol concentration in the HDL fraction was measured by enzymatic method.

\section{Results}

The mean age was significantly higher in control group than in case group $27.0 \pm 4.3$ vs. $24.4 \pm 3.6$ years respectively $(\mathrm{p}>0.002)$ (Table-I). Lower socioeconomic class was predominance in case group (58.3\%) and middle class (53.7\%) in control group (Fig-1). In terms of systolic and diastolic blood pressure, all of the patients were found normal. The mean systolic and diastolic blood pressure was significantly higher in case group compared to control group $114.5 \pm 5.0$ vs. $108.5 \pm \mathrm{J} 7.9$ respectively $(\mathrm{p}<0.001)$ (TableII). Table-III shows about $12 \%$ of patients had low HDL compared to $6.5 \%$ of controls ( $>0.240$ ). raised LDL and raised triglycerides were found in 3.3\% and 5\% of the cases respectively while non of the control group had raised LDL and triglyceride ( $>0.350$ and $p>0205$ respectively). Systolic blood pressure was positively correlated with total cholesterol and HDL ( $>0.090$ and $p>0.080$ respectively) (Table-IV) and negatively correlated with LDL and triglyceride $(p>0.166$ and $p>0.503$ respectively) the correlation of total cholesterol and HDL with diastolic blood pressure exhibit a linear relationship ( $p>0.102$ and $p>108$ respectively) while correlation of LDL and triglyceride with diastolic blood pressure demonstrates that the two variables bear an inverse correlations $(\mathrm{p}>0.455$ and $\mathrm{p}>0407$ respectively) (Table-V).

Table I: Comparison of age between two groups

\begin{tabular}{llll}
\hline Age (years) & \multicolumn{2}{c}{ Group } & p-value \\
& $\begin{array}{l}\text { Case } \\
(\mathbf{n}=\mathbf{6 0})\end{array}$ & $\begin{array}{l}\text { Control } \\
(\mathbf{n}=\mathbf{3 I})\end{array}$ & \\
\hline$<25$ & $28(46.7)$ & $8(26.8)$ & \\
$25-30$ & $24(40.0)$ & $12(39.0)$ & \\
$\geq 30$ & $8(13.3)$ & $11(34.1)$ & \\
Mean \pm SD & $24.4 \pm 3.6$ & $27.0 \pm 4.3$ & 0.002 \\
\hline
\end{tabular}

Figures in the parenthesis denote corresponding percentage; Data were analysed using Student's Test.

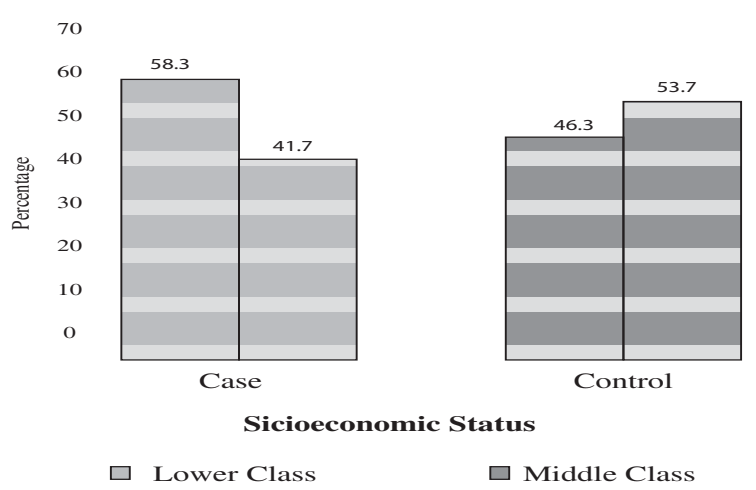

Fig. 1: Comparison of socioeconomic status between groups.

Table II.: Comparison of patients between groups by blood pressure

\begin{tabular}{lccc}
\hline Clinical Variables & $\begin{array}{c}\text { Group } \\
\text { Case } \\
(\mathbf{n = 6 0})\end{array}$ & $\begin{array}{l}\text { Control } \\
(\mathbf{n = 3 1})\end{array}$ & p-value \\
\hline $\begin{array}{l}\text { Systolic BP Normal } \\
(\leq 140 \mathrm{mmHg})\end{array}$ & $60(100.0)$ & $31(100.0)$ & \\
Mean \pm SD & $114.5 \pm 5.0$ & $108.5 \pm 7.9$ & $<0.001$ \\
Diastolic BP Normal & $60(100.0)$ & $31(100.0)$ & \\
$(\leq 90 \mathrm{mmHg})$ & & & \\
Mean \pm SD & $27.3 \pm 7.7$ & $68.6 \pm 7.8$ & 0.002 \\
\hline
\end{tabular}

\# Student Test was employed to analyse the Data and presented as Mean + SD

Table III.: Comparison of Lipid profile between groups

\begin{tabular}{llll}
\hline Lipid profile & \multicolumn{2}{c}{ Group } & \\
& $\begin{array}{l}\text { Case } \\
(\mathbf{n}=\mathbf{6 0})\end{array}$ & $\begin{array}{l}\text { Control } \\
(\mathbf{n = 3 1})\end{array}$ & P-value \\
\hline $\begin{array}{l}\text { Total Cholesterol } \\
(\mathrm{mg} / \mathrm{dl}) \leq 200\end{array}$ & $60(100.0)$ & $31(100.0)$ & ---------- \\
HDL $(\mathrm{mg} / \mathrm{dl}) \#$ & & & \\
$<40$ & $7(11.7)$ & $2(94.9)$ & \\
$\geq 40$ & $53(88.3)$ & $293(95.1)$ & 0.412 \\
LDL $(\mathrm{mg} / \mathrm{dl}) \#$ & & & \\
$\leq 130$ & $58(96.7)$ & $31(100.0)$ & \\
$>130$ & $2(3.3)$ & $0(0.0)$ & 0.350 \\
Triglycerides $(\mathrm{mg} / \mathrm{dl})$ & & & \\
$\leq 150$ & $57(95.0)$ & $31(100.0)$ & 0.205 \\
$>150$ & $2(3.3)$ & $0(0.0)$ & \\
\hline
\end{tabular}

\# Chi-square (x2) Test was employed to analyse the Data;

* Fisher's Exact Test was done to analyse the Data.

Table IV.: Comparison between lipid profiles and systolic blood pressure

\begin{tabular}{llcc}
\hline \multicolumn{2}{l}{ Correlated Variables } & $\begin{array}{c}\text { Correlation } \\
\text { coefficient (r) }\end{array}$ & p-value \\
\hline Total cholesterol & Diastolic BP & 0.164 & 0.102 \\
HDL & Diastolic BP & 0.161 & 0.108 \\
LDL & Diastolic BP & -0.075 & 0.455 \\
Triglyceride & Diastolic BP & -0.083 & 0.407 \\
\hline
\end{tabular}


Talble V: Correlation between lipid profiles and diastolic blood pressure

\begin{tabular}{llcc}
\hline Correlated Variables & $\begin{array}{l}\text { Correlation } \\
\text { coefficient (r) }\end{array}$ & p-value \\
\hline Total cholesterol & Systolic BP & 0.169 & 0.090 \\
HDL & Systolic BP & 0.175 & 0.080 \\
LDL & Systolic BP & -0.060 & 0.551 \\
Triglyceride & Systolic BP & -0.067 & 0.503 \\
\hline
\end{tabular}

\section{Discussion}

Van den Elzen were conducted a study in the Department of Obstetrics and Gynaecology, Academic Hospital Rotterdam, Netherlands. They Showed that first trimester serum total cholesterol was significantly associated with the risk of pre-eclampsia with the adjusted relative risk exceeding for women with serum total cholesterol levels above $6.0 \mathrm{mmol} / 1$ when compared with women with a cholesterol level below 5.0mmol/L First trimester serum total cholesterol also showed a significant relationship with diastolic blood pressure ${ }^{3}$.

Festus et al conducted a study in the Department of Medical Laboratory Science, Ambrose Alii Alli University, Nigeria. They stated that pregnancy has being found to be associated with changes in lipid profile and this differs with each trimester. In their study, serum total cholesterol (TC), triglyceride (TG) high density lipoprotein (HDL) and low density lipoprotein (LDL) were estimated in 120 pregnant women during normal gestation (40 in each trimester) and in 40 volunteers, apparently healthy non-pregnant women serving as control. TC, TG and HDL in the first, second and third trimesters when compared with that of the control subject were significantly high $(\mathrm{p}<0.05)$. The change inlow density lipoprotein was not significantly high $(\mathrm{p}>0.05)$ in the first trimester but became significant $(p<0.05)$ in the second and third trimester when compared with the control. Comparism between first, second and third trimesters showed that TC, TG and LDL in the 2nd and 3rd trimesters were significantly higher than in the 1st trimester. Although, not significant in the 1st trimester HDL followed similar trend. Conclusively, increase in susceptibility to the development of coronary heart disease, arteriosclerosis, hypertension and other foeta/maternal diseases associated with dyslipidaemia in the subjects studied may be unlikely since the increase in LDL is accompanied by corresponding increase in the scavenging lipid-HDL. They therefore recommend that lipid panel be part of routine investigation during pregnancy.

From this study, it can be concluded that pregnant mothers hi their first trimester had slightly altered serum lipids compared to their non-pregnant counterpart.

\section{References}

1. Piechota W, Staszewski A. Reference ranges of lipids and apolipo protiens in pregnancy. Eur J obstet Gynecol Record Med. 1992;45:27-35.

2. Winny Hirome T, Silvio M, Marcos YK Reginaldo GCL. Assessment of Serum lipids in pregnant women aged over 35 years and their relation with preeclampsia. Einstein. 2008;6:63-7

3. Van den Elzen HJ, Wladimiroff JW, Cohen-Overbeek TE, de Bruijn AJ, Grobbee DE. Serum lipids in early pregnancy and risk of pre-eclampsia. Br J Obstet Gynaecol. 1996 Feb;103:1 17-22.

4. Mazurkiewicz JC Watts GF, Warburton FG, Slavin MB, Lowy C \& Koukkou E. 'Serum Lipids, lipoproteins and apolipoproteins in pregnant nondiabetic patients 2010;47:728-31.

5. Peters JP, Heinemann M \& Man EB. 'The lipids of serum in pregnancy' J Clim Invest 1995 ;30:3 88-94.

6. Sattar N, Greer IA \& Louden J. 'Lipoprotein subtraction changes in normal pregnancy: threshold effect of plasma triglyceride on appearance of small, dense low density lipoprotein' J Clin Endocrinol Metab 1995;82:2483-91.and lipoprotein lipase activities in thyroid dysfunction - effect of treatment. Q J Med 1986:59:513-521. 